\title{
FORMAÇÃO CONTINUADA PARA NÃO DOCENTES DO COLEGIO ESTADUAL CIDADE DE CURITIBA, EM SALVADOR-BAHIA
}

\author{
Idaraí Santos de Santana ${ }^{1}$
}

\section{RESUMO}

O processo de formação de funcionários não docentes das escolas públicas, tem sido uma constante, em face destes de atuarem junto aos alunos e, assim, são indiretamente formadores do seu processo de aprendizagem. Diante dessa realidade, propomos este estudo, com o propósito de investigar, no Colégio Estadual Cidade de Curitiba, localizado no Engenho Velho de Brotas, periferia da cidade do Salvador, Estado da Bahia, a questão em torno da possível fragilidade na qualificação, da mão de obra terceirizada, evidenciando se ela compromete ou não na qualidade dos serviços prestados e, consequentemente, a inclusão dos funcionários não docentes, na terceira idade, nas discussões e deliberações da unidade escolar. A metodologia utilizada foi pesquisa de campo, mediante um estudo transversal com nove funcionários não docentes do Colégio Estadual Cidade de Curitiba, na cidade do Salvador, Estado da Bahia. Para fundamentar a pesquisa foi feita revisão de literatura, contendo aspectos relacionados à temática de formação de profissionais, Profuncionário e qualificação, como BESSA (2009), NASCIMENTO (2006), MONLEVADE (2005, 20092012 e 2014), GADOTTI (2000), BRASIL (1988), PERRENAUD (2005) e SCHÖN (2000), entre outros autores. Trata-se de uma pesquisa quali-quantitativa. Foi possível compreender que os aspectos formativos do qual são utilizados uma base curricular, utilizando o curso Profuncionário, tem a finalidade de propiciar melhoria na formação dos funcionários não docentes, considerando suas competências para auxiliar, como participe do processo de educação. Entendemos a necessidade de promover cursos para funcionários não docentes é uma premissa do cenário educativo, tendo em vista estes serem co-educadores dos docentes, onde suas competências devem ser um caminho parapromover a reflexão nos processos que envolvem a perspectiva educativa.

Palavras-chave: Formação. Profuncionário. Funcionário não docente. Competência.

\section{ABSTRACT}

The process of training non-teaching staff in public schools has been a constant, given that they work with students and, thus, are indirectly trainers of their learning process. In view of this reality, we propose this study, with the purpose of investigating, at the Colégio Estadual Cidade de Curitiba, located in Engenho Velho de Brotas, periphery of the city of Salvador, State of Bahia, the question about the possible fragility in the qualification, of the hand outsourced work, showing whether or not it compromises the quality of the services provided and, consequently, the inclusion of non-teaching staff, in the third age, in the discussions and deliberations of the school unit. The methodology used was field research, by means of a cross-sectional study with nine non-teaching staff from the Colégio Estadual Cidade de Curitiba, in the city of Salvador, State of Bahia. To support the research, a literature review was carried out, containing aspects related to the theme of professional training, Professional and qualification, such as BESSA (2009), NASCIMENTO (2006), MONLEVADE (2005, 20092012 and 2014), GADOTTI (2000), BRASIL (1988), PERRENAUD (2005) and SCHÖN 2000,

1 Mestre em Ciências da Educação pela Facultad Interamericana de Ciencias Sociales FICS.Setembro/2020; Especialista em Metodologia do Ensino, Pesquisa e Extensão em Educação pela Universidade Estadual da Bahia - UNEB (2004); Graduada em Ciências Estatísticas pela Escola Superior de Estatística da Bahia - ESEB (2002); Licenciada em Matemática pela Faculdade de Ciências Educacionais - FACE(2007). E-mail: idarais44@yahoo.com 
among other authors. It is a qualitative and quantitative research. It was possible to understand that the formative aspects of which a curriculum basis is used, using the Profuncionário course, has the purpose of providing improvement in the training of non-teaching staff, considering their skills to assist, as they participate in the education process. We understand the need to promote courses for nonteaching staff is a premise of the educational scenario, given that they are co-educators of teachers, where their skills must be a way to promote reflection in the processes that involve the educational perspective.

Keywords: Training. Professional Non-teaching employee Competence.

\section{INTRODUÇÃO}

O Colégio Estadual Cidade de Curitiba foi fundado em dezembro de 1977, cuja motivação para este topônimo ${ }^{2}$ foi uma homenagem à cidade de nascimento do então Ministro da Educação, Excelentíssimo Senhor Ney Braga. Está localizado no Engenho Velho de Brotas, periferia da capital baiana, contando, no ano de 2020, com 690 alunos matriculados nos três turnos, oferecendo à comunidade os cursos Fundamental II, Ensino Médio Regular e Curso Técnico em Administração, contando com o apoio de 25 funcionários não docentes, terceirizados através contratos estabelecidos entre a Secretaria de Educação do Estado da Bahia e empresas prestadoras dessa mão de obra.

A partir do momento em que no cenário brasileiro houve uma política educacional de universalização do acesso à Educação Básica, aumentou-se o número de estudantes matriculados e, por consequência, o quantitativo de escolas, de institutos federais, de docentes e de funcionários não docentes nas unidades escolares. Criou-se, então, grande perspectiva em torno destes últimos, visto que funcionários não docentes exercem um papel de suma importância na escola.

Desta forma, os gestores educacionais mostraram aos gestores públicos, o quanto é relevante refletir sobre a formação de funcionários não docentes nas escolas públicas, uma vez que estes atuam diretamente junto aos alunos, e assim são indiretamente formadores do processo de aprendizagem dos mesmos. O que significa que a tarefa de ensinar, não se restringe apenas a questão cognitiva, mas toda e qualquer aprendizagem que favoreça a formação integral do indivíduo e que não precisam estar relegados apenas aos docentes.

Entretanto, é importante ressaltar que, nem sempre os funcionários não diretamente ligados à docência ou às atividades de suporte ao pedagógico, têm a noção de que numa escola todos são educadores. É grande o número de funcionários

\footnotetext{
${ }^{2}$ Toponímia é a ciência que estuda a motivação dos nomes próprios de lugar (DICK, 1990).
} 
nas escolas do Brasil. E deste número, em função de não existir dado consolidado no Censo Escolar, não há como precisar o quantitativo de funcionários de escolas com habilitação em curso técnico superior.

Diante deste cenário, surgiu o Programa Profuncionário, mediante a Portaria Normativa no 25, de 31 de maio de 2007, ofertado no Estado da Bahia pelo Instituto Anísio Teixeira - (IAT) que visa promover a qualificação, possibilitando para os profissionais do interior da Bahia, diversos Polos de atendimento. Vale ressaltar que ao oferecer cursos de formação aos funcionários, se oferece, também, a oportunidade de seguimento nos estudos e uma maior coesão entre equipe diretiva e equipe de apoio.

Para tanto, as unidades de ensino precisam se posicionar quanto ao perfil desejado do funcionário e qualificações necessárias. Nesse contexto, a proposta de trabalho científico visa apresentar discussões, conceitos, definições e ferramentas às decisões tomadas para o bom desempenho dos funcionários não docentes.

Para o desenvolvimento do presente trabalho foram utilizadas pesquisas bibliográficas e de campo, além de estudo de caso. A pesquisa bibliográfica baseouse em publicações científicas na área de educação e de gestão educacional. O estudo de caso foi desenvolvido, em sua totalidade, através de pesquisa de campo, envolvendo o perfil dos funcionários não docentes, sua visão em relação a escola, avaliação geral da instituição educação e pesquisa de satisfação.

O trabalho estrutura-se em 3 capítulos, apresentando no primeiro capítulo a Formação através do Curso Profuncionário não docentes, baseado em vários autores, além da evolução e importância do planejamento do Curso Profuncionário. No segundo capítulo são abordados Resultados e Discussões a respeito do curso, destacando os conhecimentos, as habilidades e competências técnicas; apresentada a pesquisa de campo e os diversos itens que a compõe como perfil, representação gráfica dos funcionários não docentes egressos do Curso Profuncionário e no terceiro e último capítulo a avaliação e satisfação do Curso Profuncionário na visão dos funcionários não docentes do Colégio Estadual Cidade de Curitiba.

\section{METODOLOGIA}

Trata-se de um estudo de caso, tendo como corpus os funcionários não docentes do Colégio Estadual Cidade de Curitiba. A pesquisa teve como amostra 
nove funcionários, escolhidos aleatoriamente, tendo como critérios de inclusão serem egressos do Curso Profuncionários e não serem docentes. Os critérios de exclusão compreenderam aqueles já formados há mais de seis meses e/ou que tenham feito cursos similares por conta própria.

A análise dos dados foi feita mediante a análise qualitativa, ancorada nas ideias defendidas por FLICK (2013) e quanto a quantitativa, foi efetuada a fim de viabilizar a utilização comparativa, objetivando representar numericamente os dados obtidos na investigação qualitativa, ou seja, para melhor explicar o posicionamento dos respondentes sobre asquestões feitas acerca do Curso Profuncionário e da sua aplicabilidade em sua função.

\section{FORMAÇÃO ATRAVÉS DO CURSO PROFUNCIONÁRIO PARA FUNCIONÁRIO NÃO DOCENTES}

Muitas são as pesquisas e análises de estudos sobre a participação dos funcionários docentes e não docentes que atuam em ambiente escolar. Com a finalidade de compreender seus comportamentos e posturas, enquanto profissionais e a relação como indivíduos que participam de uma rede de relações na instituição.

Uma instituição de ensino não se faz somente de professores e alunos, tendo em vista a necessidade de um corpo de profissionais capacitados para que ocorra uma gestão qualificada e, sobretudo democrática. Funcionários não docentes têm porfinalidade precípua auxiliar nas ações que gerem e organizam de maneira secundárianão menos indispensável à organização da unidade escolar.

No entanto, segundo GADOTTI, (2000), é passível de observações que suas funções, bem como suas participações no contexto escolar, na maioria das vezes, nãosão valorizadas ou discutidas no âmbito que envolve as discussões intrínsecas às temáticas educacionais. Dentro desse contexto, constam de inúmeras lacunas entre a atividade que estes desempenham e o contexto educacional, especialmente no apoio aos docentes mediante ao convívio cotidiano.

As primeiras ações voltadas para a educação, no cenário brasileiro ocorreram a partir do cuidado com a criança indígena, catequizando-a através da leitura, dos bons costumes e da oração. Ensino jesuítico realizado pela coroa portuguesa e trazia a concepção de uma educação pública, mas com cunho 
religioso. Sobre a cultura organizacional e sua relação com os valores educacionais da época, podemos afirmarque:

[...] o ensino então ministrado pelos jesuítas podia ser considerado como público por ser mantido com recursos públicos e pelo seu caráter de ensino coletivo, ele não preenchia os demais critérios, já que as condições tanto materiais como pedagógicas - os prédios assim como a infraestrutura, os agentes, as diretrizes pedagógicas, os componentes curriculares, as normas disciplinares e os mecanismos de avaliações - se encontravam sob o controle da ordem dos jesuítas, portanto, sob o domínio privado (SAVIANI, 2005, p.9)

Como bem nos assegura Saviani (2005), pode-se dizer que quando se analisa os caminhos percorridos pela escola brasileira, é passível de compreensão. Neste contexto, fica claro que desde a formação da escola jesuítica até a escola do século XIX, as ações educativas não ocorriam de forma sistemática e organizada, tanto a inserção do professor caracterizado como ator principal do processo educacional, quanto do funcionário não docente que atuava e atua na escola, como coadjuvante, estava associada à organização da sociedade, seja pela família, pelo Estado ou pelas próprias instituições.

Segundo ESQUINSANI (2006), mesmo com o processo evolutivo, o que marcou a década de 1990 foi a ausência de ações visando diminuição do analfabetismo e, principalmente, da falta de recursos voltados para a educação, como um período de implantação das políticas educacionais. Somente em 1996, foi aprovada a Lei de Diretrizes e Bases - LDB (Lei no 9.394/1996). Lei que dispõe sobre a obrigatoriedade e a gratuidade para a educação básica, impondo aos poderes públicos maiores responsabilidades.

Mas, como se configurou o funcionário não docente, aquele que atua na administração escolar, no espaço escolar?

Ao se rever o processo histórico, a impressão que se tem era de uma escola composta, exclusivamente, por alunos e professores. Entretanto, de acordo com MONLEVADE (2005, p.44) "os primeiros funcionários já se faziam presentes na construção e no funcionamento da primeira escola", o que evidenciava a relevância destes para o aprendizado dos alunos. No colégio Jesuítas de Salvador, em 1550, atuavam como coadjuvantes do processo de ensino através dos cuidados com a alimentação, a religiosidade, a saúde e o desenvolvimento corporal e psicológico.

Além disso, na escola tinha "os cozinheiros, enfermeiros, sacristães, horticultores, bibliotecários, vaqueiros, administradores de fazendas, pilotos de navio, 
construtores, pintores e em outras ocupações, mais ou menos relacionadas, em conformidade com MONLEVADE (2005, p.44). Tais funcionários maximizavam valores de extrema importância na unidade escolar. Vale ressaltar que, anteriormente, quando das aulas régias, para substituir o ensino jesuítico, o ensino, escrituração e os registros das atividades ficavam, de forma, exclusiva, na responsabilidade do professor, auxiliado, algumas vezes por um escravo, cuja incumbência era de limpar o ambiente e servir água para os alunos.

No final do século XIX, a contratação de funcionários para o serviço de conservação, alimentação, cuidados da secretaria e da biblioteca, se deu em decorrência do aumento significativo de escolas primárias, o que oportunizou a uma grande demanda, uma educação mais bem-sucedida. A contratação era feita na maioria das vezes, mediante as relações de indicação política, pois concursos públicos eram feitos somente nas grandes cidades.

Historicamente, sabe-se que o Brasil saiu do autoritarismo no século $X X$, tornando-se mais democrático com a participação efetiva dos corpos docente, discente, como tambémdos pais. A habilitação dos professores ocorria mediante um curso de nível médio ou superior. Entretanto, aos demais funcionários nenhum tipo de profissionalização.

Situação esta que só foi alterada somente depois da promulgação da Constituição Federal de 1988 e da LDB, № 9.394/96, que foi segundo Monlevade (2005):

\begin{abstract}
Assegura os direitos à educação básica, à educação especial, à educação dejovens e adultos (EJA), à educação superior e à educação profissional por meio de uma gestão democrática e da garantia e a da garantia de qualidade em que pudesse alterar a situação dos funcionários administrativos sem capacitação e formação profissional para a adequação de uma ocupação reconhecida por meio de um diploma profissional (MONLEVADE, 2005, p. 63).
\end{abstract}

A implementação da lei possibilitou a inserção dos funcionários não docentes - os que atuavam na administração escolar, os colocando na posição também de educadores. Com o objetivo de excluir a situação de desvalorização e secundariedade, visto que, os funcionários têm essencial importância para a realização de bom desempenho dos alunos na unidade escolar. O autor deixa claro que, a nova legislação trouxe para o setor educacional novas obrigações e esta mudança ocorreu não só por desejo dos não docentes, mas também da base sindical e implantação de leis que eram favoráveis a formação continuada e aperfeiçoamento 
da área de atuação dos funcionários. Questões relevantes para o reconhecimento social da sua profissão de técnico em educação.

De acordo o Decreto no 5.154, de 2004 com base nas Diretrizes Curriculares da Educação Profissional, do Conselho Nacional de Educação (CNE), de acordo com Monlevade (2005, p. 42) "[...] havia inúmeras escolas técnicas públicas e privadas para a colocação de jovens e adultos ao mercado de trabalho". No que concerne a educação, desde 2005, a Câmara de Educação Básica do CNE emitiu o Parecer ํㅜ 16 e no mesmo ano a Resolução ํㅜ 5 , regulamentando a área de serviços de apoio à Educação Escolar, dos quais se destaca, dentre os vários cursos técnicos, o Profuncionário.

O Curso Técnico Profuncionário, direcionado aos funcionários não docentes, atende as áreas de habilitações: secretaria escolar, multimeios didáticos, alimentação escolar, manutenção de infraestruturas e meio ambiente escolares. Vale salientar que é ofertado pelo Ministério de Educação/MEC e Secretaria de Estado e Municipal de Educação. E tem como base os dispositivos da Resolução CEB/CNE ํㅡㄴ 5/2005, que integra as Diretrizes Nacionais sobre a Educação Profissional em Nível Médio, de modalidade semipresencial, a distância e ambiente virtual, totalizando 1.260 horas das quais 300 horas são referentes a prática profissional supervisada (Brasil,2005).

Dourado (2012) afirma que, além dos conteúdos pedagógicos que vão desde a formação da história da educação brasileira, da filosofia, da psicologia, dos direitos e deveres, além dos conteúdos específicos de sua área de atuação, os funcionários administrativos são capacitados quanto à utilização dos recursos tecnológicos em seu ambiente de trabalho.

É importante entender que a desconstrução e reconstrução da identidade são processuais. E deve ser mediada pela apropriação de informações e conhecimentos já construídos, pela edificação de novos conhecimentos e de competência para planejar e executar ações na escola, pela problematização, investigação e reflexão sobre as práticas escolares e sobre sua participação nessas práticas, como também sobre o papel social da escola e do funcionamento da escola, na qual essa perspectiva contribui para repensar acerca da atuação desse profissional educador.

O pioneirismo do Profuncionário não se deu apenas como concepção, mas se estendeu ao acompanhamento e à gestão. A Portaria Normativa ํㅡ 25, de 31/05/2007, que o institui, estabeleceu uma coordenação estadual integrada pela Secretaria Estadual de Educação, o Conselho Estadual de Educação, a União Nacional dos 
Dirigentes Municipais de Educação e os sindicatos filiados à CNTE. Esta formação técnica tem como ação primordial a valorização e a profissionalização dos funcionários administrativos, tendo como um dos diferenciais desse curso uma mudança de comportamentos desses envolvidos, tirando-os de uma função exclusivamente burocrática ou técnica e os colocando numa posição de também educadores (BRZEZINSKI, 2014).

\section{RESULTADOS E DISCUSSÕES}

O processo formativo deve necessariamente promover o desenvolvimento das competências nas atividades que se desempenha o profissional. No caso da educação, o funcionário não docente tem a competência sustentada em três pontos, identificados, por PARRY, 1996, pelo acrônimo CHA, que significa Conhecimento, Habilidade e Atitude. O Conhecimento refere-se aos saberes adquirid na escola, ou através de livros, que agregamos durante a vida, interagem e influenciam a nossa memória e podem instigar os nossos pensamentos e, consequentemente, as sínteses; quanto a Habilidade, é a prática do conhecimento na vida cotidiana, nas situações que são recorrentes diariamente; e a Atitude é o que compele o ser humano a desejar fazer algo, é o que motiva a exercitar as habilidades e os saberes adquiridos.

A gestão por competências direciona sua ação prioritariamente para o gerenciamento da lacuna $(\mathrm{GAP})^{3}$ de competências eventualmente existente na organização ou equipe, procurando eliminá-lo ou minimizá-lo. A ideia é aproximar ao máximo as competências existentes na organização daquelas necessárias para atingir os objetivos organizacionais. O conhecimento na ação é o componente que está diretamente relacionado como saber-fazer, é espontâneo, implícito e que surge na ação, ou seja, um conhecimento tácito. Sendo assim, a reflexão se revela a partir de situações inesperadas produzidaspela ação e nem sempre o conhecimento na ação é suficiente (SCHON, 2000).

Discutir competência profissional remete ao entendimento acerca de ser este um dos dilemas que sempre esteve posto para os processos educativos e que agora, em face da mediação das novas tecnologias que tornam o trabalho cada vez mais

\footnotetext{
${ }^{3}$ Termo técnico usado na área de Administração, que significa Gestão por Competência, seja no que se refere a um indivíduo ou a um grupo. É uma ferramenta que uma empresa faz uso para identificar possíveis lacunas; é identificar as possíveis carências de competência.
} 
abstrato no atual regime de acumulação, assume novas dimensões, sobretudo, no que diz respeito às competências profissionais (PERRENOUD, 2005).

Considerando o objeto de estudo, as escolas públicas estaduais do Estado da Bahia tem-se que a escola, anteriormente compreendida como espaço de ensino-aprendizagem concentrado na sala de aula, tem sido reconfigurada tornandoseespaço educativo, detentor de múltiplas tarefas, várias delas de responsabilidade dos professores, mas dos demais funcionários também, reconhecidos, como educadores. É comum encontrar pesquisas sobre políticas públicas, que consideram variáveis como a escola, a sala de aula, a formação e prática docente, no entanto, hácerta marginalização sobre os estudos voltados àqueles que também, fazem parte do processo educativo, os funcionários da escola.

O reconhecimento profissional, do saber formal e informal, dos funcionários de escola, desde o advento da Lei no 12.014/09, quando houve por bem, disciplinar as categorias de profissionais da Educação, ou seja, que alterou a Lei no 9.394/96 LDBN,tem sido recorrente, nas discussões dos sistemas de ensino.

Considerando a trajetória da profissionalização na educação, o Programa Profuncionários perpassa pela ação que é dada a importância dos funcionários como educadores. Apresentou-se no começo da década de 1990, quando houve a unificação dos trabalhadores da educação básica na CNTE. Ainda que, o sindicato aceitasse os funcionários como parte da categoria dos trabalhadores em educação, a trajetória para uma aquisição social e profissional foi extensa e existe, até hoje, preconceitos, obstáculos políticos e ideológicos. As consequências desta separação entre as categorias têm sido muito sérias. Como consequências ela reproduz, no interior das escolas, levando as desigualdades econômicas, sociais e culturais. Conforme Nascimento (2006) é considerada como:

\footnotetext{
Parte integrante de uma sociedade historicamente permeada por componentes autoritários e patrimonialistas, os funcionários da educação desempenharam papéis distintos, seja quanto à origem, seja quanto à formade ingresso e permanência, sempre em consonância com o modelo econômico, político e social vigente da época (NASCIMENTO, 2006, p.73).
}

Nascimento (2006) defende a ideia de que pode-se dizer que a sociedade antigamente pensava e agia de forma autoritária. Nesse contexto, fica claro que o papel dos funcionários não tinha notoriedade. O mais preocupante, contudo, é constatar que a função do funcionário era vista com certa irrelevância dentro da 
unidade escolar, fato esse que nos leva a inferir que o modelo da época era equivocado e que em todo esse processo ocorreu à desvalorização do profissional.

O MEC, através da Secretaria de Educação Profissional e Tecnológica (SETEC)recomendou ao CNE a inclusão, do Programa Profuncionário, nas atuais DCN para aEducação Profissional Técnica de Nível Médio de uma área específica da educação, não só para a aquisição de aptidões necessárias para um melhor desempenho das atividades educacionais, mas também como uma ferramenta importante para a construção da identidade dos funcionários da educação e também sua valorização.

Porém, pela natureza transformadora da proposta, é importante que o MEC implemente ções que viabilizem a formação profissional dos funcionários. Entendemos que uma possível ação a ser aplicada pode ser o financiamento de projetos de qualificação, com repasse de recursos para Estados e Municípios.

Mas, nas escolas públicas estaduais do Estado da Bahia, a política de valorização dos funcionários da educação constitui um programa de ações articuladasem três frentes: a) reconhecimento das novas identidades funcionais; b) oferta de escolarização, formação inicial e continuada; c) estruturação de planos de carreirae implementação de piso salarial.

O Profuncionário caracteriza-se, portanto, como uma das expressões da disposição Política do Governo Federal em adotar medidas e ações concretas de intervenção voltadas para a reconstrução da identidade profissional, da cultura e da imagem desses trabalhadores em todo o país. Vale mencionar que os dados que emergiram a partir das entrevistas semiestruturadas, embasaram a análise textual discursiva, emergindo em cinco categorias de análise: qualificação profissional e a busca do aperfeiçoamento do funcionário não docente; o curso Profuncionário e as trajetórias percorridas; contribuições que o Profucionário propiciou aos funcionários não docentes no desenvolvimento da identidade profissional; o ambiente escolar e as repercussões do curso para os funcionários não docentes; e, a voz dos entrevistados sobre o curso Profuncionário e sua proposta pedagógica.

Do total de 25(vinte e cinco) funcionários não docentes constantes no Colégio Estadual Cidade de Curitiba, apenas 9(nove) egressos do Curso Profuncionário concordaram em participar desta pesquisa.

O perfil dos entrevistados foi de faixa etária entre 50 e 65 anos (67\%), a maioria (78\%) do sexo feminino; com conclusão do ensino médio entre 35 e 50 
anos. Quanto ao trabalho profissional na Unidade Escolar, a maioria (80\%) segue atuando há mais de 30 anos no serviço público estadual, em escolas como funcionários não docentes. Foi unanimidade nas respostas dos entrevistados de que já obtiveram outra ocupação em estabelecimento privado, que não a atividade educacional. Anterior ao curso Profuncionário, 78\% dos entrevistados já haviam realizado curso de qualificação. Esses dados são de fundamental importância para compreender quem são de fatos os egressos do curso Profuncionário, objeto deste estudo, os funcionários não docentes, cujos dados compilados constam na Tabela 1.

Tabela 1 - Perfil dos entrevistados(as), egressos do curso Profuncionário

\begin{tabular}{|c|c|c|}
\hline \multirow[b]{2}{*}{ Perfil dos(as) Entrevistados(as) } & \multicolumn{2}{|c|}{$\mathrm{N}=9$} \\
\hline & $\mathbf{N}$ & $\%$ \\
\hline \multicolumn{3}{|l|}{ 1Faixa Etária } \\
\hline Entre 35 e 49 anos & 3 & $33 \%$ \\
\hline Entre 50 e 65 anos & 6 & $67 \%$ \\
\hline \multicolumn{3}{|l|}{ 2Sexo } \\
\hline Masculino & 2 & $22 \%$ \\
\hline Feminino & 7 & $78 \%$ \\
\hline \multicolumn{3}{|l|}{ 3Tempo que trabalha na escola } \\
\hline Entre 10 e 20 anos & 1 & $11 \%$ \\
\hline Entre 21 e 30 anos & 2 & $22 \%$ \\
\hline Acima de 30 anos & 6 & $67 \%$ \\
\hline \multicolumn{3}{|l|}{ 4. Trabalhou em outro ramo que não educação? } \\
\hline Sim & 9 & $100 \%$ \\
\hline \multicolumn{3}{|c|}{ 5. Já realizou cursos de Qualificação antes de ingressar no curso profuncionário? } \\
\hline Sim & 7 & $78 \%$ \\
\hline Não & 2 & $22 \%$ \\
\hline
\end{tabular}

Fonte: Autoria da pesquisadora, tomando como referência a pesquisa de campo realizada.

A representação gráfica dos principais dados do perfil dos(as) entrevistados(as),está descrito na Figura 1.

Figura 1 - Representação gráfica dos principais dados do perfil dos(as) entrevistados(as), egressos do curso Profuncionário

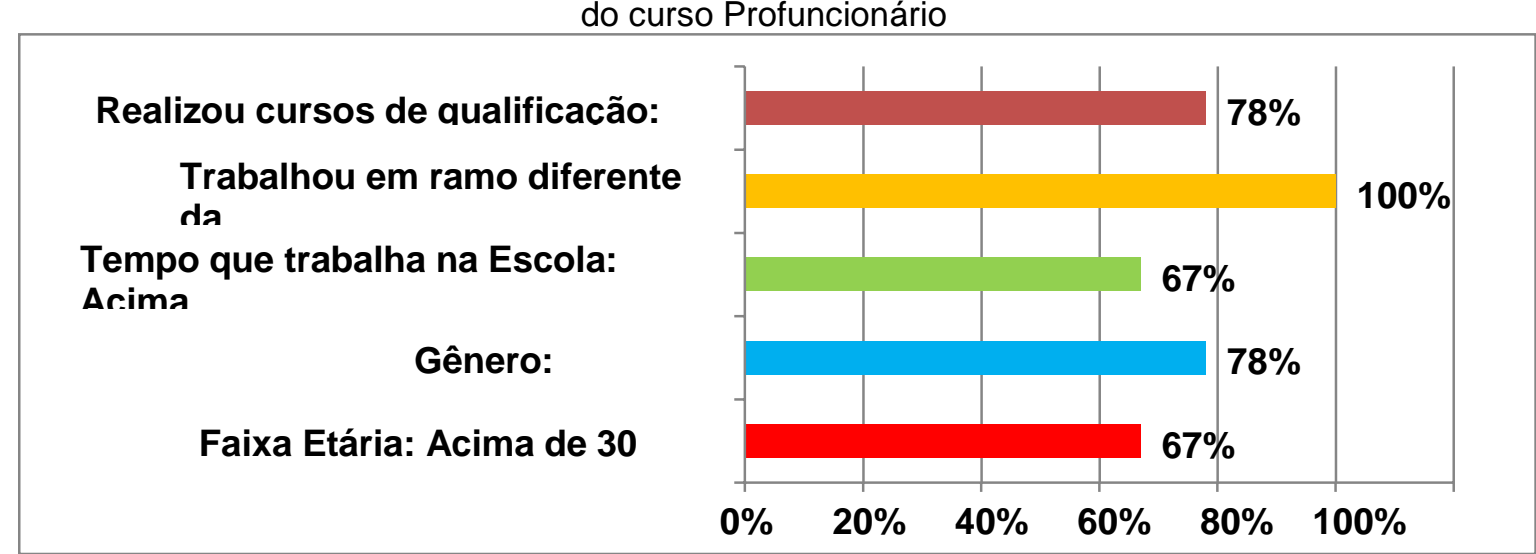

Fonte: Autoria da pesquisadora, tomando como referência a pesquisa de campo realizada. 
Diante do perfil identificado, segue-se com a análise das categorias previamente definidas, conforme o roteiro de entrevista. Por questão de privacidade, considerando a ética das informações coletadas e autorizadas pelos respectivos envolvidos, os nomes dos(as) mesmos(as) foram substituídos por E1, E2... E9, significando Entrevistado 1, Entrevistado 2, e assim por diante.

Em relação à qualificação profissional o pressuposto foi conhecer junto aos(as) entrevistados(as), egressos do curso Profuncionário, o motivo pelo qual que propiciaram o seu ingresso no referido programa de formação continuada. Foi possível compreender que a busca pelo aperfeiçoamento foi um dos motivos que as fizeram ingressar no curso, conforme descreveram E1, E2, E4; E8 e E9.

Antes do referido curso de formação continuada, havia, na Unidade Escolar, por parte dos funcionários não docentes, baixo comprometimento com a qualidade dos serviços prEstados, ausência de comprometimento com as questões relacionadas às metas, à organização, disciplina e gestão do espaço onde esses servidores desempenhavam as respectivas funções. De acordo com o que foi relatado, os funcionários integrantes deste estudo perceberam a importância do Curso Profuncionário, pois além do crescimento pessoal e profissional, eles passaram a ser vistos na escola com mais reconhecimento diante do aprimoramento de suas funções. Os depoimentos demonstram que com a proposta pedagógica do Curso Técnico em Multimeios Didáticos do Programa Profuncionário, os funcionários não docentes passaram a ter uma participação no contexto escolar de forma mais significativa.

Dentro desse contexto, reportando-se ao documento orientador (BRASIL, 2014) do Programa Profuncionário, intenciona o curso que o funcionário possibilite problematizar, ressignificando e reconstruindo as práticas de trabalho na escola, mediante o saber fazer da vivência dos funcionários no desempenho das suas respectivas funções.

Sobre essa questão, tomando como referência as ideias de Canário (2003), entendemos ser pertinente o posicionamento dos entrevistados, tendo em vista a existência de potencialidade formativa, bem como a possibilidade de articulação entre a formação e situações de trabalho.

Observa-se, também, que as situações de trabalho podem vir a ser o fazer diáriodas funcionárias de escola nas instituições em que trabalham. E, dessa forma, 
o pensamento na formação profissional, considerando essa articulação é justificado (Ibidem, 2003), tendo em vista proporcionar a produção de estratégias, de dispositivos e práticas formativas para valorizar a aprendizagem, considerando a experiência, bemcomo passa a reconhecer o papel central de cada sujeito, quando do processo de autoconstrução, não somente enquanto profissional, mas, sobretudo, enquanto pessoa.

Observa-se que a gestão educacional do Estado da Bahia exerceu um importante papel na concretude de uma política pública educacional; sobretudo, quanto à divulgação e liberação do curso aos funcionários não docentes de escola, em seus horários de trabalho, colaborando com a implantação do Programa Profuncionário no Estado.

Se por um lado existe, por parte de algumas egressas, o reconhecimento do papel da Secretaria para que houvesse a efetivação de suas matrículas no curso, por outro lado, nos relatos dos egressos E5, E8 e E3, anteriormente citados, é possível inferir que os funcionários de escola esperavam, da Secretaria de Educação do Estado da Bahia, formações que fossem direcionadas para os seus contextos de trabalho. Observa-se que essa situação também foi apontada pelos E7 e E9.

As questões trazidas nos relatos dos E7 e E9 nos leva à discussão para a problemática evidenciada no presente estudo. A primeira delas é a questão da invisibilidade dos funcionários de escola no contexto educacional (MONLEVADE, 2009, 2012, 2014), que foi em relação às auxiliares de biblioteca de uma escola no Estado da Bahia que se sentiam invisíveis, uma vez que, segundo E5, o Estado sempre proporcionava momentos de formação direcionados para os professores.

$\mathrm{Na}$ medida em que o Estado da Bahia promove momentos de formação somentepara professores, a gestão educacional, que possui um importante papel no reconhecimento e na valorização dos funcionários de escola, também como educadores, reforça a visão limitada de perceber em cena, nas escolas, somente professores e alunos (Ibidem, 2009). Além disso, vai de encontro a uma compreensão de educação mais abrangente, mencionada por Moran (2013), que considera todos os integrantes do ambiente escolar como protagonistas do processo educativo.

Reportando-se aos estudos elaborados anteriormente por Tavares e Trojan(2007), na medida em que os funcionários da escola são percebidos como educadores, cuja representação na pesquisa de campo, compreende as auxiliares de biblioteca, esses passam a exercer papéis que extrapolam o contar histórias, o que 
de suma importância no contexto educacional. Diante das análises feitas em campo e en decorrência de informações coletadas, pudemos observar que esses não docentes exercem uma função educativa junto aos alunos, participando, em determinados casos, da gestão escolar. Nesse sentido, a oferta tão-somente de cursos para contar histórias, como foi relatado pela $E 7$, percebe-se a restrição do papel desempenhado pelas auxiliares debiblioteca para essa prática, excluindo-as, portanto, das demais atividades que envolvem a educação, mesmo não sendo docentes.

É passível de entendimento que diversificadas temáticas que são tradicionalmente discutidos nas formações de professores também são de extrema relevância para os funcionários de escola, uma vez que os alunos que estão nas salas de aula com os docentes são os mesmos que frequentam as bibliotecas. $E$ os funcionários de escola, independentemente da função que exercem na instituição, assumem, em muitos momentos, assim como os professores, o papel de educadores (BRASIL, 2005). A compreensão é de que o estudo dos aspectos que têm relação direta com a aprendizagem, a inclusão e ao planejamento de práticas pedagógicas, dentre outros temas, tem enorme significância para todos aqueles que estão diariamente em contato com os estudantes, sobretudo, os profissionais não docentes. $E$, conforme o que foi identificado com o egresso E1: "a matrícula no curso me proporcionou uma maior visão na atividade que eu desenvolvo na secretaria escolar, [...]".O egresso E6, diferentemente das demais seis egressos, também trabalha no apoio da secretaria escolar e ao ser abordado pelo vice-diretor sobre a possibilidade de participar do curso, a resposta foi afirmativa, haja vista considerar relevante cursar o Técnico em Multimeios Didáticos, ofertado pelo curso Profuncionário.

A compreensão por parte da gestão educacional do Estado da Bahia no tocante à formação em serviço, que é a tônica do Programa Profuncionário, neste ponto se distingue da compreensão da Secretaria da Educação, que de certa forma não atende, na sua plenitude, a Meta 16 do PNE (BRASIL, 2014). A mesma coloca como diretriz a garantia de uma formação profissional para todos os profissionais da educação básica em sua área de atuação. No caso em específico do E6, sua participação no curso Técnico em Multimeios Didáticos foi garantida em parte, uma vez que foi liberado da escola para frequentar o curso, porém precisou cumprir a carga horária em outro turno.

Assim, considerando as respostas dos entrevistados foi possível 
compreender que a busca por aperfeiçoamento e por qualificação profissional foram os principais motivos que levaram as egressas a participarem do curso Técnico em Multimeios Didáticos, ofertado pelo curso Profuncionário.

O questionamento, no entanto, que se segue, é: Como será que foi a trajetória dos egressos ao longo do curso? Com base nessa inquietação, analisamos as questões relacionadas às facilidades e dificuldades experimentadas pelos egressos no transcorrer dos dois anos do curso.

Em relação às trajetórias pessoais, os relatos dos egressos sobre suas histórias pessoais ao longo do curso possibilitou compreender 0 seu comprometimento, principalmente, no que disse respeito ao desafio de conciliar múltiplas atividades, conforme relato da E2: "Sem dúvida, foi um sufoco o planejamento do espaço e tempoque me possibilitasse a divisão das tarefas com a família, trabalho e estudo, porque par ao estudo requer muita determinação em consonância com a organização, disciplina e comprometimento".

O destaque dado foi para as trajetórias aqui descritas de relatos das entrevistadas do sexo feminino. E, reportando-se as ideias de Moita (2007, p. 134), tem-se que: "as mulheres, enquanto humanos biossociais diferenciados, tiveram posicionamentos específicos ao longo da história e nas diversas culturas". Quando se analisa, de forma breve, entende-se que ao longo da história e nas diversificadas culturas, o percurso das mulheres na sociedade foi de luta por espaço, buscando a longa data, igualdade para a condição no mundo do trabalho e nos espaços formativos.

O entendimento adveio das narrativas das egressas, que são mães, evidenciaram a tensão em conciliar a vida familiar, a vida de estudante e a vida profissional, conforme relatos de E2, E7 e E5.

As narrativas evidenciadas corroboram com o ponto de vista de Moita (2007) aodiscorrer que durante a infância dos filhos, as mulheres passam por períodos de grande tensão, pois elas têm de conciliar da melhor forma possível o trabalho, os estudos e a disponibilidade para os filhos.

Dessa forma, quando E5 coloca que todas são guerreiras e profissionais multitarefas, traduz a luta diária de muitas mulheres. A mensagem de parabenizar a todas, inclusive aqueles que acompanharam as egressas ao longo do curso, reconhece as trajetórias de todos que fizeram parte do curso Técnico em Multimeios Didáticos. 
Quanto ao percurso da formação dos funcionários de escola por meio do Programa Profuncionário, aqui representado pelo curso Técnico em Multimeios Didáticos, se organiza a partir de diretrizes curriculares com ênfase na formação de educadores, na formação em serviço e na formação na modalidade a distância (Idem, 2014). Essas diretrizes sustentam a organização didático-pedagógica vivenciada pelas egressas, sujeitos desta pesquisa, ao longo do curso.

Atrelado a isso, foi possível entender também, que dentre a relação dos aspectos pessoais, durante a vigência do curso, as facilidades encontradas enfrentadas pelos entrevistados foram em parte ao tempo disponível (E6). Alguns entrevistados (E3; E5; E7) mencionaram que tiveram dificuldades com os conhecimentos disponibilizados sobre a informática e uso de computadores.

$O$ receio e o susto inicial, indicados por E3 e E7 são frequentes, em estudantes, no momento de sua primeira experiência com a modalidade a distância, especialmente quando não dominam ferramentas básicas de informática, como foi o caso de E7 que, no início do curso, tinha receio até mesmo de ligar o computador.

Diante disso, o papel dos professores e dos tutores no processo da EAD é de fundamental importância. Na modalidade presencial o processo de ensino é, tradicionalmente, conduzido pelo professor, na EAD esse processo é desdobrado entre o professor formador e o tutor (PEREZ, 2016).

No Programa Profuncionário, a equipe é composta por professores formadores, tutores a distância e tutores presenciais. Os encontros presenciais são conduzidos pelos tutores presenciais. A estes cabe a interação com os estudantes, seja instigando-os a fazerem todas as atividades propostas pelos professores formadores (ARRIAL, 2016), ou auxiliando no enfrentamento das dificuldades que surgem ao longo do curso, como o uso das tecnologias.

Moore e Kearsley (2008) utilizam-se da seguinte argumentação em relação às responsabilidades dos professores formadores e dos tutores:

[...] ajudam os alunos a aplicar aquilo que estão aprendendo, na medida
em que colocam em prática aptidões que viram ser demonstradas ou
manipulam informações e ideias que foram apresentadas. [...] são
responsáveis por testes e avaliações formais e informais, criados para
assegurar que o aluno está progredindo. [...] proporcionam conselhos,
apoio e incentivo a cada aluno [...] (MOORE e KEARSLEY, 2008, p. 152-
153).

A importância desse conjunto de responsabilidades, registrado pelos autores (Ibid), fica evidente no momento em que as egressas E2 e E5 recordam do 
apoio e das orien;tações recebidas no decorrer do curso.

A interação entre estudantes, professores formadores e tutores, como pode ser observado nas falas das egressas, foi valorizada. Corroborando essa perspectiva, para (MOORE e KEARSLEY, 2008), os estudantes da modalidade EAD geralmente, consideram estimulantes e motivadores essa interação com a equipe de professores e tutores e com os colegas, tanto no que se refere ao conteúdo do curso, quanto ao apoio emocional que surge dessa interação, denominada pelos referidos autores de interação social.

Já E2, E4, E7 e E8 relataram que as maiores dificuldades compreenderam o sentimento em relação ao aprendizado, sobretudo, nas questões de Educação a Distância (EAD).

Sobre essa questão, a compreensão de Silva (2009) é de que a EAD se apresenta como possibilidade para a democratização de acesso ao conhecimento. Para a concretização desse acesso, são necessários requisitos mínimos de infraestrutura para esta modalidade de ensino, dentre os quais: adequação física do Polo de Apoio Presencial; internet disponibilizada para o acesso ao Ambiente Virtual de Aprendizagem - AVA; laboratórios e salas de aulas para os encontros presenciais; biblioteca; salas de uso administrativo para funcionários, professores e tutores (PEREZ, 2016).

Já em relação ao aprendizado, comungam do mesmo pensamento as E4 e E7, por sua vez, ressaltaram como desafios o quantitativo de conteúdos e a dificuldade em relacioná-los com o seu cotidiano. As disciplinas mencionadas pertencem ao núcleo Formação Pedagógica e são ministradas nos módulos 1 e 2 docurso. Nessa disciplina, os estudantes têm acesso a informações que ajudam na compreensão do que é e como se estrutura um curso ou um programa de Educação a Distância (BRASIL, 2012). E, dessa forma, a dificuldade encontrada pelas egressas E4 e E7 em relacionar a teoria com o seu dia a dia pode estar ligada à sua experiência com EAD, uma vez que tanto o seu percurso formativo anterior ao curso, quanto a sua prática na escola, estão vinculados ao ensino presencial. A segunda disciplina listada, Educação, Sociedade e Trabalho, possue como ementa:

Análise da sociologia como resposta intelectual às transformações sociais resultantes da Revolução Industrial, do Industrialismo e da Revolução Francesa. Descrição dos elementos e características do Funcionalismo e do Materialismo Dialético. Interpretação da Educação na perspectiva 
conservadora: o registro conservador de Émile Durkheim e a influência do pensamento liberal de John Dewey e da teoria do Capital Humano. Interpretação da Educação na perspectiva crítica: educação como reprodutora da estrutura de classes ou como espaço de transformação social. Estudo sobre a Reestruturação capitalista, reformas do Estado e o mundo do trabalho: o desenvolvimento das relações de trabalho na história da humanidade. Estudo sobre a reestruturação do modo de produção capitalista. Análise das reformas do Estado, do papel da escola e do compromisso social dos trabalhadores da educação (PPC, 2014, p. 25).

A disciplina, conforme sua ementa apresenta aspectos sociológicos da educação. É uma ementa extensa, com estudo de diferentes teóricos, configurando- se em uma disciplina profunda e densa. Se comparada com uma disciplina que se preocupa com a relação entre Sociologia e Educação no contexto do Ensino Superior, é possível perceber que possui similaridades, justificando, assim, os depoimentos de E4 e E7 de ser uma disciplina muito teórica.

Outra dificuldade relatada dos entrevistados foi com a infraestrutura. Como são semelhantes, expõem-se as explanações das egressas E1, E2 e E8, no início do curso, onde o Polo de Apoio Presencial apresentou problemas.

O fato de a EAD utilizar meios e tecnologias de informação e comunicação (BRASIL, 2017) exige especial atenção à disponibilidade de internet e computadores em condições de funcionamento. Esses requisitos são primordiais para uma formaçãoque se propõe na modalidade a distância. Para Perez (2016), os fatores relacionados à infraestrutura necessitam ser constantemente (re) avaliados, sobretudo, em função da dinamicidade de atualizações tecnológicas e de manutenções necessárias devido aos desgastes temporais.

$O$ entendimento é de que esses fatores influenciam no bom desenvolvimento do curso, principalmente quando um estudante possui acesso a esses recursos somente no Polo de Apoio Presencial. Todos os entrevistados mencionaram que em relação às facilidades encontradas o apoio familiar e dos colegas foi fundamental para a realização do curso, bem como sua continuidade.

No que diz respeito às contribuições que o Profuncionário propiciou aos funcionários não docentes no desenvolvimento da identidade profissional, como seu próprio nome diz, trata-se de um programa de formação profissional em serviço, por isso, os funcionários de escola que participam do programa são reconhecidos como funcionários estudantes (BRASIL, 2014). Nesse sentido, a relação com o ambiente detrabalho ocupou, assim como as trajetórias pessoais e os percursos formativos, lugarde destaque durante o processo de formação. 
As egressas E1 e E4 mencionaram que durante o período em que estavam em formação foi possível aplicar, no ambiente escolar, aprendizagens que estavam sendo construídas no curso. As possibilidades proporcionadas às egressas colocaram de certa forma, essas funcionárias de escola em cena, uma vez que suas aprendizagens ganharam espaço no ambiente escolar.

Essa abertura por parte das escolas foi destacada por E1 e E4 como uma experiência facilitada durante o curso. E mencionada pelas egressas E1, E3, E4, E5,E7 e E8, a liberação das escolas para frequentarem os encontros presenciais, exceto o E6 descrito anteriormente, que teve dificuldade de liberação.

O reconhecimento por parte da gestão da importância da qualificação profissional dos funcionários de escola surge como resposta ao movimento que iniciou na década de 1990 pelo reconhecimento e valorização da categoria (MONLEVADE, 2009). E8 enfatizou o quanto se sentiu valorizada em poder cursar e ser liberada do turno de trabalho e também, o quanto esses aspectos foram determinantes para o seu ingresso e permanência no curso. Já E6 e E9, diferentemente das demais egressas, sentiram certa resistência por parte daequipe diretiva da escola e dos colegas de trabalho para frequentar o curso. Mesmo tendo sido uma determinação da Secretaria de Educação do Estado da Bahia, liberaros funcionários de escola para participarem do Programa Profuncionário, neste caso, isso não foi suficiente para que a equipe diretiva e os colegas de escola compreendessem a importância da qualificação profissional para ambas.

A reconstrução das identidades profissionais a que se propõe o Programa Profuncionário, aqui representado pelo curso Técnico em Multimeios Didáticos, supõe o princípio da construção de conhecimentos. Os conhecimentos historicamente produzidos e apropriados pelos funcionários estudantes ao longo do curso podem ser reconstruídos pelos funcionários de escola à medida que necessidades situacionais próprias vão surgindo (BRASIL, 2014). E, através do empoderamento teórico, é possível problematizar a vivência e as práticas escolares, conforme relato da egressaE5:

No contexto do Programa Profuncionário, problematizar a vivência e as práticas escolares sugere confrontar conhecimentos, valores e habilidades, que estão presentes no fazer cotidiano, com outras visões, concepções, propostas, paradigmase teorias (Ibidem, 2014). No caso da E5, isso ocorreu quando se deu conta das relações que são estabelecidas na escola e, com base nos 
conhecimentos construídos, refletiu sobre elas.

Interessante perceber que, a partir do seu reconhecimento enquanto profissional da educação, as egressas E3 e E9 conseguiram problematizar e refletir sobre as relações entre professores e os outros funcionários de escola.

Além disso, por meio dos trabalhos iniciais de observação, desenvolvidos no curso, E3 e E9 perceberam a forma como os demais funcionários de escola eram tratados pelos estudantes:

\begin{abstract}
E3: "No início do curso eram muitas as atividades de observação, sobretudo, na observação dos alunos no ambiente da escola que com o curso o olhar mudou. Minha escolha foi pela cozinha e pelo refeitório,bem na hora da merenda, para compreender o tratamento dispensado. Os alunos não respeitavam os funcionários da merenda!"

E9: "Quando das atividades de observação na área de merenda escolar, percebi o desrespeito que os alunos tratam as funcionárias. Como se elas não tivessem nenhum valor. No meu papel na biblioteca,trabalhei na hora de leitura, separando as leituras, que tratavam de respeito ao próximo, salientando a importância de respeitar o lado humano, especificamente as merendeiras, salientando sempre as palavras mágicas: "obrigado", "com licença", "por favor".
\end{abstract}

As atividades de observação, mencionadas pelas egressas E3 e E9, foram desenvolvidas no Núcleo de Formação Pedagógica do curso, nos módulos 1, 2 e 3. Nesse núcleo está prevista, entre outros temas, a questão da identidade do técnico em educação enquanto educador. Além disso, os componentes curriculares desse núcleo buscam ampliar e movimentar o olhar dos funcionários sobre a escola e, nesse aspecto, repensar e reorientar suas práticas e as relações que são estabelecidas na escola.

A partir dos relatos da E3 e E9, é possível perceber que os temas trabalhados nesse núcleo repercutiram no desenvolvimento da identidade profissional das egressas, bem como, no reconhecimento dos demais funcionários de escola no ambiente escolar.

Para Bessa (2009), a organização pedagógica do Programa Profuncionário visa, entre outros aspectos, à problematização da realidade escolar, por meio da abordagem de questões específicas, teórico-práticas, possibilitando, assim, uma compreensão mais abrangente, a partir de diferentes perspectivas. Os relatos das egressas sobre se sentirem mais seguras, encorajadas, críticas, autorizadas a argumentar, dar opiniões e problematizar realidades, com sustentação teórica, como nos casos de E3 e E5, evidenciam a importância do enfoque trabalhado no 
decorrer do curso para que as egressas pudessem se considerar, assim como os professores, profissionais da educação.

Nessa direção, as egressas E2, E4 e E8 pontuaram como contributo do curso no desenvolvimento da identidade profissional a própria questão de se reconhecerprofissional da educação e com importante papel:

Franzoi (2006), ao discorrer sobre o tema profissão, aponta a importância do conhecimento adquirido por um indivíduo na construção de sua profissão. Como mencionado anteriormente, o Programa Profuncionário possui como um de seus princípios a construção de conhecimentos. Partindo dessa perspectiva, há um ponto de convergência entre o entendimento do autor e a proposta do Programa Profuncionário, em detrimento aos relatos das egressas: a importância da construção do conhecimento por parte das egressas e sua repercussão no desenvolvimento da identidade enquanto profissionais da educação. Nesse caso, o processo formativo ocorrido no curso Técnico em Multimeios Didáticos possibilitou a apropriação, por parte das funcionárias de escolas, conhecimentos que possibilitaram que elas se reconhecessem enquanto profissionaisda educação.

A assertiva trazida (Idid, 2006) é de que a profissão resulta da articulação entre o conhecimento adquirido pelo indivíduo, o reconhecimento social da função que ele desempenha, em função do conhecimento adquirido, e o reconhecimento pelo próprio sujeito que é portador do conhecimento adquirido. Este processo de reconhecimento e reconstrução da identidade profissional das egressas é também um lugar de lutas e conflitos, uma vez que, de acordo com Nóvoa (2007), a identidade profissional se constrói em meio a lutas e conflitos.

Não diferente considerando os dados produzidos junto aos entrevistados, a compreensão é pode ser em sintetizados em torno da perspectiva do empoderamento. Consoante Horochovski e Meirelles (2007), a definição de empoderamento muitose aproxima do entendimento de autonomia, uma vez que se refere à capacidade de o sujeito poder decidir sobre as questões que lhe dizem respeito. O processo identitário, no dizer de Nóvoa (2007), passa pela capacidade de o sujeito exercer comautonomia a sua atividade, por meio do sentimento de que controla o seu trabalho.

\section{CONSIDERAÇÕES}

A presente investigação possibilitou reconhecer as potencialidades 
educativas do Colégio Estadual Cidade de Curitiba, para além da sala de aula; uma reflexão acerca dos benefícios e dificuldades do Curso Profuncionário diante de novos saberes dos funcionários. A percepção que os funcionários não docentes têm é de que na escola, em diferentes ambientes, é possível alçar novos patamares, explorar todas as potencialidades educativas disponíveis.

De modo geral, os funcionários não docentes demonstraram compreender que os professores podem ser auxiliados por esses servidores em uma prática de trabalho coletiva. E, para tanto, necessitam estar devidamente instrumentalizados de forma continuada para o desempenho das suas funções, daí a importância de se manter tal prática no Colégio Estadual Cidade de Curitiba, com vistas à formação profissional dos funcionários da escola, haja vista que são sujeitos imprescindíveis para fazer acontecer a educação intraescolar. Vale ressaltar que o Programa Profuncionário é o único programade formação profissional ofertado nacionalmente, voltado para essa categoria de trabalhadores.

Dada a importância do tema, promover cursos para funcionários não docentes é uma premissa de cenário educativo, tendo em vista estes serem coeducadores dos discentes. Suas competências e os saberes formalizados devem ser um caminho para promover a reflexão e qualificação nos processos que envolvem a perspectiva educativa dos profissionais não docentes da Unidade de Ensino investigada, podendo ser extensivo para as escolas estaduais do Estado da Bahia.

Diante dos relatos dos entrevistados, ficaram evidentes as mudanças ocorridas posteriores ao curso são paulatinas, mas na medida do possível, têm sido importantes pelo fato de agregar os saberes apreendidos teoricamente no curso com a prática profissional, tendo em vista a eficácia das atividades desenvolvidas, considerando as competências utilizadas para a melhoria da função desempenhada, com notoriedade inclusiva no contexto em que cada um se insere.

Nesse sentido, o Curso Profuncionário permitiu aos funcionários não docentes mediarem processos de ensino/aprendizagem de forma enriquecedora, interferindo diretamente na aprendizagem dos discentes de forma significativa. Junto aos entrevistados, houve unanimidade em dizer que o curso impactou de forma positiva todo o ambiente escolar. 


\section{REFERÊNCIAS}

BESSA, D.D. Profuncionário: curso de formação para os funcionários da educação. Brasília: Revista Retratos da Escola, v. 3, n. 5, p. 485-487, jul./dez. 2009.

BRASIL. Constituição da República Federativa do Brasil, 05/10/1988. Brasília: SenadoFederal, 1988.

BRASIL. Lei № 9.394/96 dispõe sobre a Lei de Diretrizes e Bases da Educação Nacional.Brasília: Ministério da Educação e Cultura, 1996.

BRASIL. Resolução CNE/CEB n 5, de 22 de novembro de 2005. Brasília: MEC, 2005.

BRASIL. Lei no 13.005/14 dispõe sobre o Plano Nacional de Educação (PNE), garantindo avalorização dos profissionais da educação. Brasília: MEC, 2014.

BRASIL. Orientações Gerais. Brasília: Ministério da Educação, 2017.

BRZEZINSKI, I. Formação de profissionais da Educação e mudanças da LDB/1996: dilemas e desafios? Contradições e compromissos? In: BRZEZINSKI, I. (Org.). LDB/1996 contemporânea: contradições, tensões, compromissos. São Paulo: Cortez, 2014.

DICK, M. V. de P.do A. A motivação toponímica e a realidade brasileira. São Paulo: Geo Arquivo do Estado, 1990.

DOURADO, L. F. Caderno de estudos do profuncionário: Gestão em Educação Escolar. 4aㅡ. Ed. atualizada e revisada. Cuiabá: Universidade Federal do Mato Grosso/ Rede e-Tec Brasil 2012.

ESQUINSANI, R.S.S. et al. Gestão e políticas educacionais: do que estamos falando, mesmo? Aportes teóricos-conceituais para delimitação de termos. In: CAMARGO, I. de. (Org.). Gestão e políticas da educação. Santa Cruz do Sul: EDUNISC, 2006.

FLICK, U. Introdução a metodologia da pesquisa: um guia para iniciantes. São Paulo: Editora Pensa, 2013.

FRANZOI, N.L. Entre a formação e o trabalho: trajetórias e identidades profissionais. Porto Alegre: Editora da UFRGS, 2006.

GADOTTI, M. Perspectivas atuais da educação. Porto Alegre: Ed. Artes Médicas, 2000.

HOROCHOVSKI, R.R.; MEIRELLES, G. Problematizando o conceito de empoderamento. Seminário Nacional Movimentos Sociais, Participação e Democracia, 2007.

MOITA, M.da C. Percursos de formação e de transformação. In: NÓVOA, A.(Org.). Vidas de Professores. Portugal: Porto Editora, 2007. 
MONLEVADE, J.A.C. História e construção da identidade: compromissos e expectativas.Revista Retratos da Escola, Brasília, v. 3, n. 5, p. 339-351, jul./dez. 2009.

MONLEVADE, J.A.C. Profissionalização ou terceirização? Passado, presente e futurodos funcionários técnico-administrativos da educação básica pública no Brasil. Brasília: Edição do Autor, 2014.

MOORE, M.G.; KEARSLEY, G. Educação a distância: uma visão integrada. São Paulo:Cengage Learning, 2008.

MORAN, J.M. A educação que desejamos: novos desafios e como chegar lá. São Paulo:Papirus, 2013.

NASCIMENTO, F.C.F. Funcionários da Educação: da constituição da identidade à açãocomo co-gestores de escola. Brasília: FE-UnB, 2006.

NÓVOA, A.(Org.). Vidas de Professores. Portugal: Porto Editora, 2007.

PEREZ, E.M. Evasão na EAD: estudo de caso do Programa Profuncionário do IFSul. 2016. 138f. Dissertação (Mestrado Profissional em Educação e Tecnologia) Instituto Federal Sul-rio-grandense - IFSul, Pelotas, 2016.

PERRENOUD, P. Escola e cidadania. O papel da escola na formação para a democracia.Porto Alegre: Artmed Editora, 2005.

PARRY, Scott B. The quest for competencies. Training. Jul. 1996.

SCHÖN, D.A. Educando o profissional reflexivo: um design para o ensino e aprendizagem. Porto Alegre: Artmed, 2000.

SILVA, L. M. da. Educação inclusiva e a formação de professores. Monografia. Curso de Especialização Latu Sensu à distância em Educação Profissional e Tecnológica Inclusiva. Universidade do Estado do Mato Grosso - Campus Cuiabá. Cuiabá,2009.

TAVARES, T.M.; TROJAN, R.M. O funcionário escolar como educador: formação dos trabalhadores em educação da rede estadual de ensino do Paraná. Uberlândia: Revista Eletrônica em Extensão, 2007. 